\title{
JORGE BASADRE GROHMANN EL HISTORIADOR DE LA REPÚBLICA
}

Juan Carlos Valera Huarcaya'

\section{EL HISTORIADOR EN VIDA:}

El oír el nombre del señor Jorge Basadre Grohmann (Tacna, 12 de febrero de 1903 - Lima, 29 de junio de 1980) es recordar los libros de la historia del Perú en la época escolar o universitaria (para ser más precisos el libro "Historia del Perú")- o en su defecto por los billetes de cien nuevos soles (S/. 100) que se encuentran en actual circulación y que hace poco tuvo algunos cambios estéticos en el diseño pero sin omitir la presencia de esta noble figura de la historia peruana en muchos ámbitos, ya que referirse a este emblemático personaje es referirse la tradición y a la facilidad de plasmar los hechos que datan desde épocas anteriores al nacimiento de la República de nuestro país. El recordado historiador se desempeñó en diferentes ámbitos; tales como en el plano educativo donde se desempeñó como el catedrático más joven de su alma mater la Universidad Mayor de San Marcos, con tan solo ventaseis años, en el año 1928. También destacó en el plano político, llegando a ser Ministro de Educación en dos ocasiones, en el año de 1945 y de 1956 a 1958. Además de dar grandes aportes a la educación y cultura del Perú, también tuvo bajo su responsabilidad el compendio de la Historia del Derecho Peruano, hecho en el año 1937. Siendo éste un texto base en la formación de futuros profesionales de la facultad de Derecho y que hasta la actualidad cumple con esta finalidad.

Basadre Grohmann nace en la ciudad de Tacna el 12 de febrero de 1903. hijo de Carlos Basadre Forero, ingeniero de minas y político por excelencia en su natal Tacna, y de la señora Olga Grohmann Butler quien fuera dama ilustre de la comunidad. Cabe resaltar que en aquella época. Tacna que vio nacer a este gran historiador estaba ocupada por el país vecino de Chile, esto era debido a los estragos de la etapa de la posterior de la Guerra del Pacifico -que aunque se contaba con un plebiscito del Tratado de Ancón de 1883- este ultimo no se había hecho efectivo aún.

Basadre inició su educación en el Liceo Santa Rosa, esta escuela era una de las pocas que funcionaban en Tacna debido a que la ciudad estaba en un proceso de la llamada "chilenizacion", es decir toda exhibición de símbolo patrio o el simple hecho

\footnotetext{
1 El presente In Memoriam esta dedicado a cada uno de los miembros y ex miembros de la Revista Athina, debido a que si no fuera por ellos, nada de esto habría sido posible.

2 BASADRE. Jorge Historia del Perú. Lima, Lexus Editores, 2000. ISBN 9972-625-35-4
} 
de entonar del himno nacional estaba terminantemente prohibido. A los nueve años de edad, toda su familia se traslada a la ciudad de Lima, en la capital es donde continua su educación, Ilegando a estudiar en el Colegio Alemán Deutsche Schule (ahora Colegio Alexander von Humboldt) donde concluyó su educación secundaria en aquel entonces se concluía los estudios secundarios en cuarto año- en el año 1918, ahora en el Colegio Nuestra Señora de Guadalupe. Al año siguiente, en 1919, ingresaría a la Universidad Mayor de San Marcos ${ }^{3}$, donde obtuvo los grados de Doctor en Letras, en Jurisprudencia y el título de abogado (dato que hasta la fecha muchos desconocen). En el año 1922 se incorporó a la Facultad de Jurisprudencia donde concluye sus estudios en el año 1926 (antes de tiempo, en solo cinco años), ésto se debió al viaje que hizo en el año 1927 con motivo del plebiscito, que mencioné con anterioridad, producto del cual debido interrumpir sus estudios en la Facultad .En 1928 se gradúa de Bachiller en Letras y es ahí donde optó por el grado de doctor con su tesis titulada "Contribución al estudio de la revolución social y política de! Perú durante la República".

Se puede afirmar que en esa época es donde termina de definir su profunda afinidad por la patria, debido a la formación académica, y filosófica que recibió en la Biblioteca Nacional. Un dato de interés es que con respecto a su casa de estudios, solía afirmar que no aprendió nada ${ }^{4}$, esto queda demostrado en los siguientes fragmentos extraído de una de sus obras, Ilamada "La vida y la historia":

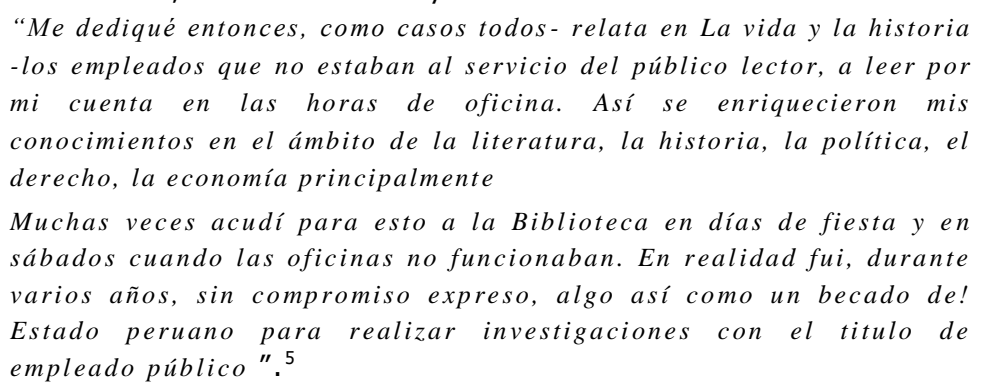

Hay una gran crítica que Basadre hace a la metodología de enseñanza y a biblioteca de su Universidad en el mismo libro, la cual dice así:

"En realidad, la universidad y, especialmente la Facultad de Derecho, simplemente "efectuaba una tarea estricta deformación profesional" En su metodología de la enseñanza predominaba la pura exégesis legalista. No se prestaba tampoco una sistemática atención de las cuestiones sociales; los trabajos de investigación eran escasos; los estudiantes leían poco a los grandes tratadistas; se editaban muy pocos libros de Derecho, y la biblioteca no cubría la producción mas novedosa"6

Como bien se mencionó en un inicio, un aspecto importante enla vida del historiador Jorge Basadre, es que fue el catedrático más joven de la Universidad Mayor de

3 INTERNET http://www.unmsm.edu.pe/

$4 \quad$ Tengo total convencimiento que es lo que lo llevaría a ser uno de los ejes fundadores de la Nueva Biblioteca Central (luego de su incendio) y apegarse más a la labor de historiador que la de abogado o político, como en algún momento tuvo ciertas tentaciones de seguir.

$5 \quad$ BASADRE, Jorge. La vida y la historia.

$6 \quad$ Ibidem. p.279. 
El Historiador de la República

San Marcos, donde inició a dictar en el año 1928 la cátedra del curso de Historia del Perú, expresando ciertos dilemas con respecto a la valoración otorgada a diversas piezas literarias, lo cual expresó en diversas publicaciones de la época. Además de ser el catedrático más joven, también fue invitado por el nuevo rector Alejandro Deústa, para leer un discurso académico en presencia del Presidente de la República de ese entonces, Leguía y otros altos mandos del país, entre los que estaban el ministro Pedro Oliveira ${ }^{7}$. En este discurso. Basadre expuso ante una gran multitud, su visión extensa de lo que es "La multitud, la ciudad y el campo en la historia del Perú". Básicamente lo que daba se desarrolló en dicho discurso fue el papel que juegan las masas frente al llamado individualismo y el reciente providencialismo, a su vez se trató el largo trayecto histórico frente a la coyuntura, fugaz de los hechos y de los notorios personajes de la historia. Quedó muy claro que al ser abordado el tema de providencialismo, sucedáneamente este hecho fue tomado como una acusación a la tribuna oficial. Aunque se buscó salvaguardar la cortesía del caso, nuestro historiador siguió ahondando en el tema, acción que no fue del agrado de las autoridades, siendo notorio el desagrado al momento de extender los saludos correspondientes entre ambas partes al momento de concluir la ceremonia. Cabe resaltar que las desavenencias entre Basadre y las autoridades oficiales del gobierno de Leguía se prolongaron durante mucho tiempo, al punto que en diversas ocasiones era aprensado por las autoridades, como en la ocasión que fue enviado a las islas de San Lorenzo después de un discurso de ideas ceñidas al corte del punto de vista de José Carlos Mariátegui. Las criticas del historiador hacia el gobierno de tumo se basaban en el carácter compulsivo del gobernante ya que asemejaba la forma de gobierno a una especie de mita colonial ${ }^{8}$.

\section{$1 \mathrm{~L} \underline{\text { LA "POLITICA" }}$}

La política no fue ajena para Basadre (pero no fue su campo de mayor desempeño) ya que fue miembro asiduo del grupo Reforma Universitaria, dicho movimiento se inició en Córdova por la lucha de sus estudiantes. Es lo que podemos llamar el "nacimiento de una nueva generación de estudiantes latinoamericanos" ya que si bien cada protesta tenia su propia razón, se tenía un mismo lenguaje; el cual era la necesidad de ser escuchados, de cambiar el orden ya establecido en busca de una forma de tener una figura heroica producto de la posguerra y de la crisis mundial, eventos que prácticamente empujaron a los jóvenes latinoamericanos a buscar dicho cambio. Hay que hacer hincapié en la negativa de los docentes universitarios frente a los principios de dicho movimiento, pero con un favorable contexto político lograron el reconocimiento debido. Además Basadre fue parte del muy célebre Conversatorio Universitario del año 1919. junto a jóvenes promesas de la época, tales como: Manuel Abastos. Ricardo Vegas García, Raúl Porras Barrenechea, Luis Alberto Sánchez, Guillermo Luna Cartland, Carlos Moreyra y Paz Soldán y Jorge Guillermo Leguía, aunque el dato curioso es el que nos otorga el gran historiador actual Carlos Ramos Núñez sobre dicho acontecimiento que dice así: "Basadre es mencionado frecuentemente como miembro del Conversatorio, aún cuando él mismo nunca se reconocería como tal, sino tan solo como un oyente de las conferencias que pronunciaban los alumnos de mayor edad. Su presencia en una famosa fotografía había sido fruto de la casualidad". ${ }^{9}$

\footnotetext{
$7 \quad$ Ibidem, p.279.

8 BASADRE, Jorge "La conscripción

№3 (Junio de 1924), págs. 21-26.

$9 \quad$ RAMOS NÚÑEZ, Carlos. "Jorge Basadre: Historiador delDerechoy comparatista", $\quad$ 2da edi-

ción. Editorial Grijley, 2009.

vial".Novecientos, Año 1(Abril de 1924), págs. 26 - 34,
} 
Siguiendo con su vida estudiantil, tenemos que en el año 1920 viajó a la cuidad del Cusco como delegado del primer Congreso Nacional de Estudiantes que fue organizado en conjunto por la Federación Nacional de Estudiantes y por algunos alumnos de la Universidad San Antonio Abad, buscando impulsar una reforma universitaria, tan propias de la época. En dicho viaje se contó con la presencia del presidente de la Federación, Víctor Raúl Haya de La Torre y con la presencia de Raúl Porras. En dicho viaje, el comportamiento de Basadre mostraba cierta peculiaridad; nuestro historiador se mostraba como el miembro más callado y reservado de la delegación, algo en su momento resultó ser inexplicable para Luis Eduardo Valcárcel, pero que fue plasmado en un breve pasaje de las memorias informativas de dicho autor, las cuales describen el acontecimiento de recibir a Basadre en la ciudad imperial del Cusco:

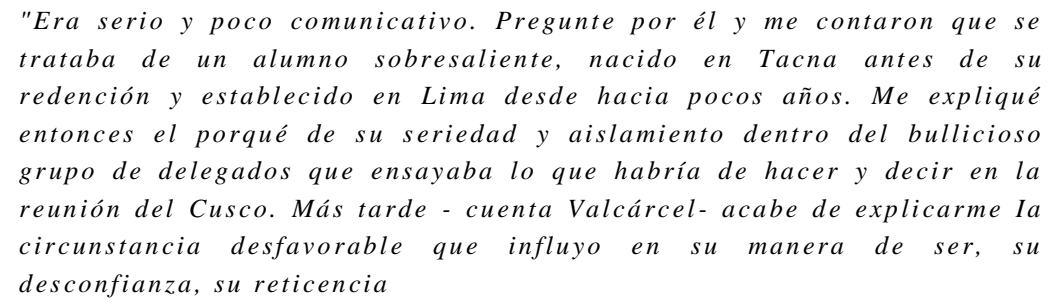

\section{EL HITO BIBLIOTECARIO}

Ahora bien siguiendo con la vida de nuestro historiador, una gran importancia en su vida significó; la Biblioteca Central de la Universidad Mayor de San Marcos y la Biblioteca Nacional". En la Biblioteca de su Universidad se inició como redactor del llamado Boletín Bibliográfico, a la par de su reconocida labor como docente en dicha casa de estudios. Ejercida luego de su labor en la delegación enviada a la comisión plebiscitaria de Tacna y Arica, punto en el que ahondaré més adelante, siguiendo con la noble labor de Basadre. fue llamado en el año 1930 y en el año 1935 a ser director de la Biblioteca Central ${ }^{12}$., desempeñando en sus dos períodos de mando, una labor impecable, que hasta la fecha sigue siendo referencia a seguir en muchas Bibliotecas Universitarias. Su labor en la Biblioteca Nacional no fue diferente, iniciándose como voluntario en 1920, luego fue auxiliar y después conservador en el año 1926, sin descuidar sus demás ocupaciones, tales como ser el jefe del servicio nocturno de la Biblioteca de San Marcos. El hecho de pasar gran parte del día en la biblioteca resultó fundamental para su futuro intelectual y académico, es más en un texto auto bibliográfico, confesaría: "me formé en la Biblioteca Nacional más que en la Universidad"11. En 1943 producto del Incendio de la Biblioteca Nacional, fue designado por el gobierno de Manuel Prado y Ugarteche como Director General de dicha casa de conocimiento, siendo así considerado como el tercer fundador de la

\footnotetext{
10 VALCARCEL, Luis E. Memorias, Lima: Instituto de Estudios Peruanos, 1981, p267.

11 VID. PLANAS, Pedro. La república autocratica. Lima: FundaciónFredrich Ebert, 1994

12 Revista universitaria. Año XXIV. Volumen II, 1930, pag 433. Mediante una resolución de fecha 14 de junio de 1930. Firmada por el Rector Alejandro Desutra y el Secretario. Lizardo Alzamora Silva, por acuerdo del Consejo Universitario de la época y atendiendo al fallecimiento del doctor Luis Varela Orbegoso, el joven Basadre es nombrado Bibliotecario de la Universidad.

13 Biblioteca Perú vivo: Jorge Basadre. Lima: Librería -Editorial Juan Mejia Baca. 1966. Pag.9.
} 
Biblioteca, debido a que hasta el año 1948, fue el artífice de diversos cambios motivo de la reconstrucción y reestructuración, tales como: la publicación de Revista Fénix' ${ }^{\prime 4}$ la Revista Anuario Bibliográfico Peruano ${ }^{15}$ y la creación de la Escuela Nacional de Bibliotecarios en el año 1944, donde a su vez se dedicó a la recolección de nuevos fondos bibliotecarios los cuales permitirían a la Biblioteca ser "la más grande de América Latina" de la época. Su periodo de dirección duro hasta el año 1945.

\section{LOS VIAJES DEL SABER FUERA DEL CONTINENTE}

Basadre viajó por muchos países para continuar con su formación intelectual, llegando a países como : Estados Unidos, Alemania y España: viajes en los cuales aparte de adquirir un gran conocimiento, también experimentó diferentes vivencias las cuales lo marcaron para llegar a ser el reconocido historiador que es considerado hasta la fecha. La primera incursión de nuestro historiador se dio en el año 1931, en el mes de setiembre, donde gracias a una beca otorgada por la Fundación Camegie, obtenida por la gestión de José Antonio Encinas, viaja a los Estados Unidos de Norteamérica para estudiar la organización de bibliotecas (visitando de manera frecuente la Biblioteca del Congreso de Washington), cabe resaltar que en esa época el país atravesaba una seria crisis económica, conocida como la "depresión", su estancia no fue muy prolongada, ya que en vista del cierre de la Universidad Mayor de San Marcos -luego de la caída de Leguía- se enrumba hacia el viejo continente en el año 1932, llegando a Alemania en búsqueda de más conocimiento, prolongando su estancia hasta diciembre de 1935.

Teniendo las facilidades del Instituto Iberoamericano de dicho país, pasando gran tiempo en la Universidad de Berlín, conociendo allá al profesor Richard Thrunwald, del cual aprendió los avances de la etimología jurídica germana ${ }^{16}$. También tuvo gran acercamiento al profesor Frederich Meinecke el cual lo instruyó de una manera más amplia en los campos del Estado y el llamado Derecho Público. Lo relata el mismo Basadre de la siguiente manera:

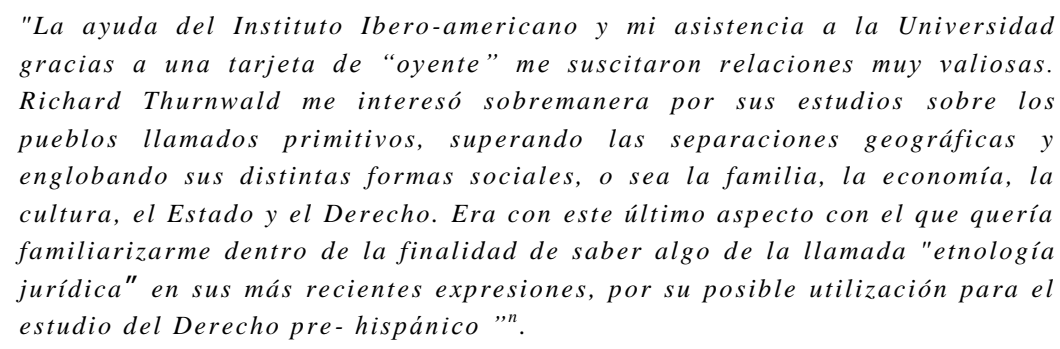

La experiencia de Basadre en Alemania, junto a Thurnwald le sería fundamental en el desarrollo de una metodología que se halla muy presente en sus textos de Historia del Derecho, el cual es el denominado: método comparatista, en la contraposición de los estudios de las culturas antiguas y modernas de cada lugar. Con respecto a esa metodología de las culturas antiguas se pronunciaría a favor, pero con

INTERNET, http://wwvv.bnp.gob.pe/portalbnp/inde.l.php.

INTERNET, http://books.google.com.pe/books/about/Anuario bibl iogr\%C3\%A 1 fico_peruano.

BASADRE, Jorge. La vida y la historia, op.cit, págs. 527-622.

Ibidem. Pag. 534. 
ciertos reparos en algunas ocasiones, quedando demostrado en su obra "La vida y la historia", al expresar que era un gran error el estudiar las culturas antiguas solo con los vestigios que han persistido, llegando al punto de despreciar el método comparativo; debido a que "al no ser utilizado con suma cautela puede llegar ser contraproducente" 18. Dichos estudios fueron de gran utilidad, así como su acercamiento con Thumwald, debido a que gracias a ello puedo hacer una correcta sección del Derecho inca en su cátedra de Historia del Derecho Peruano y a su vez llegó a aproximarse a la técnica y a la metodología de la historia del Derecho como disciplina con una identidad propia ${ }^{19}$. Pero ahí no quedaron los conocimientos adquiridos por nuestro historiador, ya que también se nutrió de las primeras monografías de Heinrich Trimborn, sobre la etnología jurídica americana, cuya base sería posteriormente disertada en el Centro de Estudios de Sevilla en el año $1933^{20}$.

El paso por la biblioteca tenía que ser algo cotidiano para Basadre, acudiendo así casi todos los días a las bibliotecas de Berlín donde frecuentaría los libros de los grandes fundadores de la antropología jurídica en general: Bachofen, Summer Maine, Morgan, Radcliffe Broun, Robert Lowie siendo estos los máximos exponentes de la materia y también de la etnología jurídica germana, pasando por diferentes matices como los evolucionistas, teniendo a su máximo exponente Albert Hermann Post (1839$1895)$ en su obra Materiales para la ciencia jurídica universal del Derecho ${ }^{2}$. A su vez también leyendo la obra de Josehp Kohler (1849-1919), comparatista de las formas jurídicas de los pueblos antiguos, que señalaba que el Derecho era un fenómeno inherente a cada civilización, en lugar y época determinada. También tuvo afinidad con el círculo comparativista de la Zeitschrift ftrvergleichende Rechstswissenschaft (una revista de la ciencia jurídica comparada de la época) y también con respecto a las obras de Graebner, Koppers y Schmidt ${ }^{22}$. Se concluye que su estancia en el país germano amplió de sobremanera sus conocimientos en Derecho Romano, materia que estudió de manera exigua en la Univerdidad de San Marcos, a su vez, estudiar el idioma alemán, para una mayor comprensión de los textos de la zona, así como también a diversos autores exponentes de la Escuela Histórica del Derecho.

Ahora su travesía lo llevaría a otro país del viejo continente, pero ya no sería a un país de lengua extranjera, sino a España. Fue a dicho país debido a su estancia en este país el motivo por el que no regresó a San Marcos en parte, debido además que se encontraba clausurada. Así que nuestro historiador, ante la carencia de recursos, fue movilizado en tren en el mes de setiembre del año 1932, haciendo una pequeña parada en París para luego ir a España. En París acudió donde un familiar suyo, el Ministro de Perú en Francia, Francisco García Calderón Rey (aunque dicho acercamiento fue inútil). Quien sí fue de gran ayuda fue el hermano del Ministro, Ventura García Calderón, quien consigue presentar a Basadre con Carlos Espía (político gallego republicano, que ejercía el cargo de Subsecretario en el Ministerio de Gobernación), que a su vez lo presentó con Claudio Sánchez Albornoz, rector de la Universidad de Madrid, dicho encuentro fue descrito por Basadre de la siguiente manera:

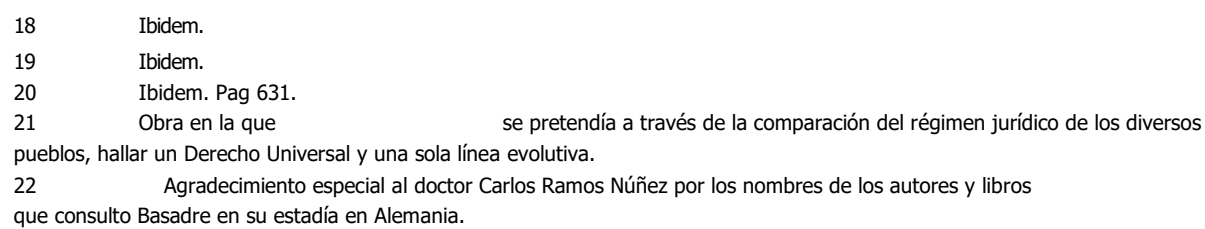




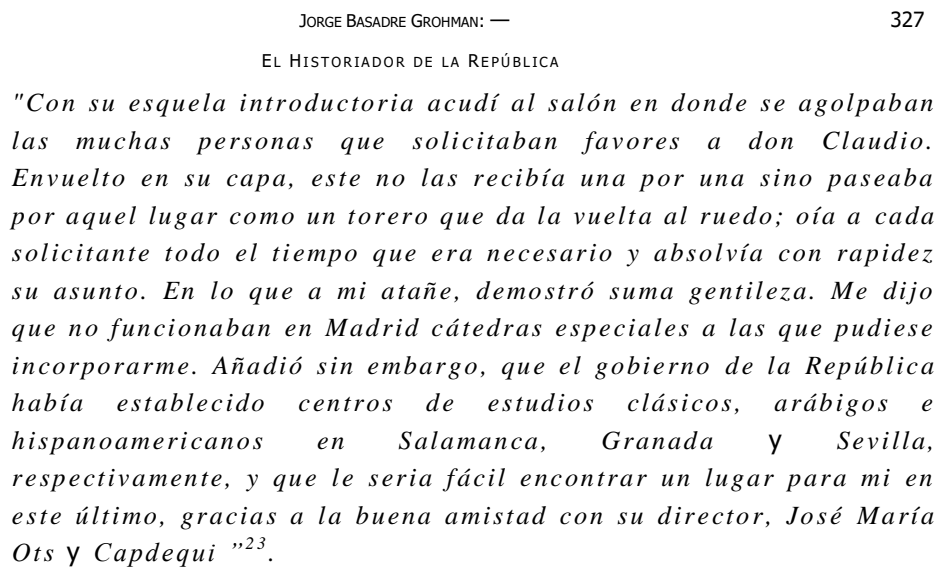

Fue entonces que Basadre se traslado a Andalucía, donde lo esperaba una persona que marcaría su vida de ahí en adelante; el profesor de Derecho Indiano de la Universidad de Sevilla, José María Ots, cita el cual fue uno de los más grandes acontecimientos de su vida ${ }^{24}$ y también resolvió de manera rápida la falta de empleo de Basadre, dándole empleo en el Centro de Estudios Hispanoamericanos (ahora Instituto). Al culminar su contrato con dicho establecimiento fue contratado por el profesor Ots para realizar pesquisas sobre legislación indiana del siglo XVI11. Dichas indagaciones de nuestro Historiador se dieron en el Archivo de las Indias. Archivo Histórico de Madrid y en el Archivo del Palacio Real.

A su vez Basadre investigaba sobre temas de su interés en sus ratos libres, los cuales estaban pactados con el profesor Ots. Todo parecía indicar que España experimentaría un crecimiento intelectual imparable puesto que se daban todas las condiciones para dicho logro, hasta que sobrevino la derrota de la República, que trajo como consecuencia el abandono del país por parte de muchos de los estudiosos que Basadre conoció, buscando ahora una nueva vida en América Latina, pero siendo rechazados en nuestro país por las clases altas, sabiendo el desmedro que significaría el no aceptarlos para enriquecer la vida cultural y económica de otros países del continente, siendo así aprovechados por países como México, Chile, Colombia. Venezuela y Bolivia $^{25}$. Dicha actitud solo traería una consecuencia negativa en el necesitado desarrollo de la ciencia jurídica peruana y atrasaría el progreso de la Historia del Derecho, especialmente del llamado Derecho indiano ${ }^{26}$. Luego de dichas experiencias en Europa, el mismo Basadre reconoce que fue vital para su desarrollo en los conocimientos que tenía de la Historia del Derecho, de alguna u otra forma, se podría describir ios conocimientos adquiridos de la siguiente manera: "Alemania; para sus estudios de Derecho Precolombino, España; para el Derecho Indiano o Colonial y su visión del Derecho Romano, Derecho Medieval, Derecho Canónico y Derecho Moderno se ampliarían a merced de su experiencia bibliográfica en Norteamérica" 27 Tenemos que luego de dichas experiencias se llegara a definir el rubro de la Historia que será la especialidad de Basadre, poniendo un alto en su interés por la historia

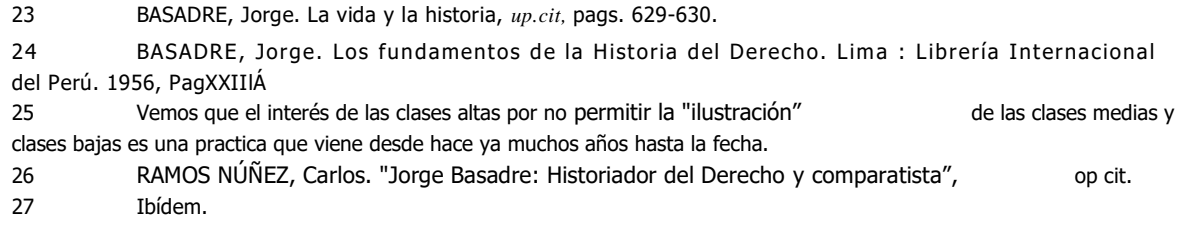


política y social en general, llevando ahora su interés en la Historia del Derecho Peruano. Al parecer la razón más significativa que lo llevó a elegir dicha rama de la Historia fue la necesidad de renovar los contenidos bibliográficos, debido a que luego de revisar el manual de Román Alzamora ${ }^{2}$ y la "nueva" edición del hijo de este último, Lizardo Alzamora ${ }^{29}$, además de los trabajos de otros autores los cuales seguían siendo vacíos y carentes de fuentes ejemplares para el enriquecimiento de la materia. Dicho lo anterior, se afirma que Basadre sería el gran inaugurador de la histiografla jurídica moderna en el Perú.

\section{EL MANUAL DE LA HISTORIA DEL DERECHO PERUANO Y LOS FUNDAMENTOS DE LA HISTORIA DEL DERECHO}

Con esta novedosa obra, titulada "Manual de la Historia del Derecho Peruano", Basadre busca así dar al fin una correcta elaboración de la historia social del Derecho, buscando de esta menera marcar una gran diferencia con el hispanismo y el positivismo legalista que imperaba en los estudios de la época. La idea del manual, era para uso académico, pero como podemos apreciar hasta la fecha, dicho objetivo no se ha cumplido a cabalidad. Siguiendo con la elaboración del manual, dicho manuscrito fue publicado en el año 1937 en el mes de agosto, en la ciudad de Lima, teniendo a Basadre de vuelta en nuestro país. Fue publicado por la Editorial Antena, siendo parte de la "Biblioteca Peruana de Ciencias Jurídicas y Sociales" que estaba inaugurando dicho establecimiento ${ }^{30}$. Este primer trabajo se dividió en tres tomos los cuales se dividían de la siguiente manera: "Nociones Generales", "Época prehispánica" y "el desenvolvimiento del Derecho Peruano desde la época de la conquista española", luego en las ediciones dadas a futuro, se incorporaría "la época republicana" dando así origen a un cuarto tomo, el cual agrupaba varios textos independientes escritos después de 1937. tales como: "Antecedentes del Código Civil del 1852", "Hacia una interpretación histórica del Código Civil de 1852" y "Contribución al estudio del derecho anterior al Código Civil de 1852", los cuales fueron publicados en revistas de la Universidad Mayor de San Marcos ${ }^{31}$.

Como se mencionó con anterioridad si bien Basadre fue un gran historiador, su obra no fue presentada como la obra maestra de la época sino fue presentada como "apenas un ensayo provisional" y es que lo que podía suceder con el Manual es que siga la misma suerte de los ya publicados por Román Alzamora en $1876^{32}$ y por Eleodoro Romero Salcedo en $1901^{33}$, se hace la siguiente advertencia en su manual:

"El presente libro es apenas un ensayo provisional. Si el destino de las obras de Historia es marchitarse pronto por los incesantes descubrimientos

\footnotetext{
28 ALZAMORA. Román. Curso de Historia del Derecho Peruano. Lima: 1876.

29 ALZAMORA, Lizardo. Curso de Historia del Derecho Peruano. Lima : 1941.

30 BASADRE, Jorge. Historia del Derecho Peruano (Nociones generales. Epoca

Fuentes de la época colonial). Biblioteca Peruana de Ciencias Jurídicas y Sociales, Volumen

prehispánica.

1, Lima: Edi torial Antena S.A., 1937

31 BASADRE, Jorge. "Antecedentes del Código Civil de 1852", "Hacia una interpretación histó

rica del Código Civil de 1852" y "Contribución al estudio del derecho anterior al Código Civil de 1852 ", aparecidos en la Revista de Derecho y Ciencias Políticas de San Marcos en 1939, 1942 y 1952.

$32 \quad$ ALZAMORA, Román. Curso de Historia del Derecho Peruano. Lecciones dadas en la Facultad de Derecho por el profesor Román Alzamora. Lima: Imprenta del Estado, 1876.

33 ROMERO SALCEDO, Eleodoro. Derecho Peruano. Segunda Parte. Resumen de las lecciones dadas por el catedrático del curso en la Facultad de Jurisprudencia. Lima: Tipografía Italiana, 1901.
} 


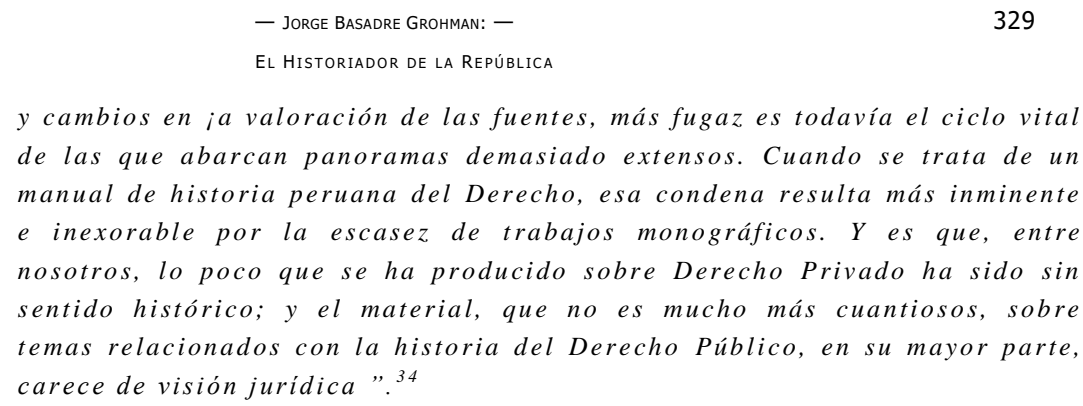

y cambios en ia valoración de las fuentes, más fugaz es todavía el ciclo vital de las que abarcan panoramas demasiado extensos. Cuando se trata de un manual de historia peruana del Derecho, es a condena resulta más inminente e inexorable por la escasez de trabajos monográficos. Y es que, entre nosotros, lo poco que se ha producido sobre Derecho Privado ha sido sin sentido histórico; y el material, que no es mucho más cuantiosos, sobre temas relacionados con la historia del Derecho Público, en su mayor parte, carece de visión juridica". ${ }^{34}$

Lo que veremos es que no fue así, ya que esta obra de Jorge Basadre es la segunda obra más consultada que tiene, detrás de "Historia de la República del Perú, la multitud, la ciudad y el campo y Perú: Problema y posibilidad". Y su obra menos consultada es "Fundamentos de la Historia del Derecho", esto se debe a su denso contenido teórico, pero lo que hay que resaltar sobre su Manual es que a más de setenta años de publicada, viene siendo aún consultado por jóvenes universitarios y esto se debe en gran medida a que no hay aun un trabajo que logre innovar en dicha área hasta la fecha. Siguiendo con el manual de Basadre, cabe mencionar que nunca desconoció el aporte hecho por sus antecesores académicos, ya que como el mismo menciona: "eran la obra de profesores empeñosos, que querían dar a sus alumnos una guía en la compleja materia que les toca estudiar" ${ }^{\prime 35}$, hay que mencionar también al profesor de la Universidad de San Agustín, Juan Manuel Arévalo, el cual publicó en 1927 Ios "Apuntes de Historia del Derecho Peruano"36, a su vez en 1909 dio un bosquejo para el público estudiantil Ilamado "Resumen de las lecciones de Historia del Derecho Peruano", ambos trabajos pueden ser calificados como material de consulta para la enseñanza, como un intento de exégesis, es decir que iba a seguir la suerte de las obras de Alzamora y Romero, mientras que el manual de Basadre, a pesar de ser una obra de síntesis para el alumnado, la diferencia que lo distancia de sus antecesores es la búsqueda de la interpretación histórica y también en el interés de incorporar a las primeras manifestaciones de Derecho indígena, antes de la conquista española, pero como dato adicional tengo que señalar que no se trato al Derecho Republicano en esta primera edición del Manual. Teniendo a su vez que Basadre, según Ramos Núñez: "no situó su manual de Historia del Derecho Peruano como un trabajo de Historia del Derecho privado, sino más bien en el ámbito de la Historia general del Derecho" ${ }^{37}$

Siguiendo con las grandes obras de Basadre, tenemos que la publicación que siguió al Manual de Historia del Derecho Peruano, fue llamada "Fundamentos de la Historia del Derecho", el cual fue publicado casi a 20 años de la publicación del Manual, esta vez la editorial Liberia Internacional del Perú fue la encargada de dicha publicación, el dato curioso es que los Fundamentos nace como una futura segunda edición del Manual, ya que su redacción empezó un año después de la publicación de éste, en el año 1938 y que tuvo ciertas pausas tales como : la reconstrucción de la Biblioteca Nacional en el año 1943 o en el año 1948, donde viaja a Washington, es recién en el año 1951, año en el que regresa a Perú y retoma la producción de los Fundamentos, viéndolo como "la oportunidad, por tanto tiempo esquiva de proseguir

\footnotetext{
$34 \quad$ Historia del Derecho Peruano (1937) Advertencia.

35 BASADRE, Jorge. Los fundamentos de la Historia del Derecho op. Cit. P. 149

36 ARÉVALO, Juan Manuel, Apuntes de Historia del Derecho Peruano. Arequipa: Tipografía Medina, 1927.136 paginas.

37 RAMOS NÚÑEZ, Carlos. "Jorge Basadre: Historiador del Derecho y comparatista", op cit.
} 
las notas iniciadas en $1938^{\prime \prime}{ }^{38}$. Siguió con sus escritos a pensar de nuevos viajes, pero dentro de todo ello, Basadre pudo compartir con Helen L. Clagett, que era la directora de la Sección de Derecho de una Biblioteca en Estados Unidos -para ser mas precisos la biblioteca del Congreso de dicho país- la cual tenía catálogos específicos con la cultura jurídica de varios países. Todos ellos siendo indispensables para ser un historiador del Derecho $^{30}$, además de consultar la nueva bibliografía de la Universidad Mayor de San Marcos, teniendo una obra de lenta maduración y con una gran densidad teórica, siendo esta obra una de las mejores de Latinoamérica, pero también siendo de las menos consultadas por los académicos.

Los Fundamentos de Basadre, como también lo hizo con el Manual, se divide en varias partes: "La teoría de la historia del Derecho", "La técnica de la historia del Derecho", "La pro fundidad del Derecho en el tiempo", "Los elementos jurídicos llegados al Perú a partir del siglo XVI: sus orígenes históricos" y finalmente "Los caracteres originales de la historia del Derecho Peruano". Todos estos capítulos no habrían sido posibles si no fuera por la adecuación del método a la materia y no la materia al método (lo cual es muy común en varias investigaciones), buscando así Basadre que su obra perdurara y no feneciera como le pasó a varios investigadores de la época, es por eso que también vemos una gran amplitud metodológica en esta obra, a su vez es muy notorio el cambio que hay en el autor desde su "Manual de Historia del Derecho Peruano" hasta la publicación de "Fundamentos de la Historia del Derecho", podemos notar que hay su intelecto maduro, dejando de lado el eclecticismo metodológico que llevaba. Basadre hace una breve pero interesante descripción de lo que es la Historia del Derecho: "Se trata de vitalizar la historia del Derecho estableciendo una relación funcional de ella con la historia de la cultura, sin hacerle perder su propia independencia" ${ }^{40}$.

Podemos concluir que para el conocimiento de la historia del Derecho se requiere el conocimiento de varias ciencias, primando las ciencias sociales y culturales, pero para el desarrollo óptimo de dicha rama de la historia se requiere un gran conocimiento en las llamadas ciencias jurídicas ya que sin ellos se tendría sin sentido dicha rama. Quedando en claro que será la cual forme parte de la sociedad actual, de la política que nos rige, mentalidades colectivas e individuales, así como la cultura pero no se mezclan en uno solo sino que son vistos con detenimiento dentro del sistema jurídico vigente buscándole así explicación a su devenir. Y teniendo que Basadre buscó la explicación de las variables de la historia como la historia de cada pueblo y no hacer divisiones historiográficas como hacían muchos autores.

\section{COROLARIO:}

El trabajo de Jorge Basadre, no pasaría desapercibido. Es por eso que a lo largo de su vida y después de su muerte fueron surgiendo diversos discípulos, unos habiendo tenido mayor contacto con Basadre que otros. Tal es el caso de Javier Vargas, el cual fue su asistente de cátedra en el año 1935 para el curso de Historia del Derecho Peruano, fue de vital apoyo, ya que el Manual de Historia del Derecho Peruano tiene varios apuntes de clase tomados por Vargas, al cual también el mismo Basadre hace un

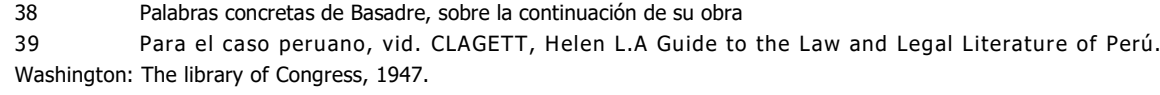


Agradecimiento especial por el apoyo brindado en ese tiempo. Siendo Vargas el único discípulo cercano de Basadre, que no abandonó los estudios histórico -jurídicos. Ya que en 1937 optó por el desarrollo de diversos estudios entre ellos, los varios trabajos de investigación sobre el Derecho precolombino. ${ }^{41}$

Luego llegarían dos nuevos asistentes de cátedra, José Merino Reyna y Bemardino Villegas Ramos, para el año 1936, pero quedando un poco confusa la influencia de Basadre en ellos dos, debido a que a diferencia de Basadre, su campo de investigación no tenía mucho que ver con lo que habían visto con el historiador durante los tiempos de cátedra en San Marcos. La justificación de lo afirmado se encuentra en los trabajos de investigación posteriores a 1937, teniendo que Merino Reyna optó por la investigación en el campo del Derecho positivo y que Villegas Ramos opto por las nuevas figuras civiles de la época. Luego de estos tres investigadores, llegaron a aparecer diversos autores pero así como Merino Reyna y Villegas Ramos, no tenían una clara influencia de Basadre en sus trabajos, hasta la aparición de Vicente ligarte del Pino con sus publicaciones "Historia de la Facultad de Derecho e Historia de las Constituciones del Perúm ${ }^{42}$, el cual fue recomendado por el mismo Basadre para continuar con sus estudios documentales en Londres.

Posteriormente teniendo los trabajos de Femando de Trazegnies, Domingo García Belaúnde, Carlos Fernández Sessarego, así como las publicaciones del mismo Jorge Basadre Ayulo ${ }^{41}$, muestra también una mediana o escasa relación con lo publicado o enseñado por el historiador tacneño. Puedo afirmar que hasta la fecha, el Manual de Historia del Derecho peruano fue la obra que marcó a Basadre con respecto a su calidad como historiador, ya que fue tal el impacto de la obra que la que la sucedió, en este caso "Fundamentos de la Historia del Derecho" de 1956, solo fue una obra más del historiador, al no proponer un modelo nuevo de propuestas metódicas, pero siendo a su vez una lectura obligada para todo aquel que desee un análisis extensivo de la Historia del Derecho, más allá de fechas y hechos, que se encontrara con un contenido muy denso, pero que el tiempo tomado en entenderlo será del todo valioso. los Incas. Lima: Colegio de Abogados de Lima, 1988; Historia del Derecho Peruano. Parte Genera] y Derecho incaico. Lima: Universidad de Lima, 1993.

$42 \quad$ UGARTE DEL PINO, Vicente. Historia de la Facultad de Derecho. Lima: UNMSM, 1968; Historia de las Constituciones del Perú. Lima: Editorial Andina 1978.

$43 \quad$ Hijo (ya fallecido) de Jorge Basadre Grohann con Isabel Ayulo La-Crox. 